\title{
莒麦種子の発芽時における糖の消長について \\ Changes of Sugar Contents and Free Sugars during the Germination of Buckwheat (Fagopyrum esculentum Mönch)
}

（昭 和 41 年 9 月 8 日 受 理)

\author{
高 橋 美 帆下 村 得 治 \\ (Miho Takahashi) (Tokuji Shimomura)
}

The present investigation was undertaken to see changes of sugar contents and free sugars during the germination of buckwheat.

As the result of germination, total sugar and polysaccharide decreased remarkably and soluble sugar and reducing sugar increased simultaneously, after a while each sugar content getting into a state of equilibrium.

Free sugar constituents of the seed and seedlings of various germination stages were determined by the use of paper chromatography and thin layer chromatography.

In buckwheat seed were found sucrose, raffinose and stachyose. During the germination these three sugars still continued to exist, while glucose, and a little later, fructose gradually appeared. Also in the latter half of the germination were found isomaltose and isomaltotriose (?).

The content of sucrose was in the highest degree of all the sugars throughout the process. The rates of raffinose and stachyose increased in the latter part of the germination.

緒

著者らは著麦の $\alpha$-glucosidase の研究を行なってい るがその際, 蓓麦種子の発芽に伴 5 糖の変化についても 検討を加えたので報告する。

植物種子の発芽時の糖組成の変化については米 ${ }^{1)}$, 小 麦 ${ }^{2)}$, カラマッ種子 ${ }^{3)}$, エンドウ豆 ${ }^{4)}$ の報告, D. Koller et al. 5) の総説, 中山 ${ }^{6)}$ の著書などがある。

その植物源によって糖の消長はやや趣きを異にしてい るようである。例えば, 米, カラマッ種子, 大麦では未 発芽時には sucrose, raffinose, glucose が存在し, 発 芽後 raffinose は全く認められないと報告され, また最 近, 松下 ${ }^{7)}$ は蔬菜類の遊離の糖について, 大部分の発 芽種子には raffinose は認められなくなっていたと報告 しているが，蓄麦では未発芽時に glucose は認められ ず, raffinose は発牙後す継続して認められた。また, 米や大麦で発芽時に maltose の存在が報告されている が薷麦では全く認められず， isomaltose の存在が認め られたなどである。発芽時の isomaltose の存在につい ては緑麦芽の報告 ${ }^{8)}$ があるが, 溯粉分解醉素作用との関 連性からす著麦種子の発芽に伴って isomaltose が一時 的にあらわれるといらことは興味深いことに思われる。 sucrose が常に存在し, 発芽に伴って glucose, fructose が增加する傾向にあるのは, いずれの種子であ同じょう である。

\section{実 験 方 法}

\section{1. 試料調製}

1964 年度北海道産の蓄麦種子 (Fagopyrum esculentnm Mönch)を用いた。種子を $0.5 \%$ さらし粉に 5 分 間浸漬洗滌後, 水に浮ぶ種子を除去して $26 \sim 28^{\circ} \mathrm{C}$ の暗 所で発芽させた。各発育段階に応じて生長のよくそろっ たものを 50 本ずつ 2 組とり, 洗條後風乾, 糖の分析に 用いた。

\section{2. 糖含量の測定}

1）全糖一風乾試料の 1 組を乳鉢て粉末とし， $25 \%$ 塩 酸 $20 \mathrm{ml}$ と水 $200 \mathrm{ml}$ を加えて煮沸している湯浴内て 2 時間半加熱, 放冷後沪過, 汇夜を $10 \%$ 水酸化ナトリ ウムで微酸性に中和，全量を $500 \mathrm{ml}$ とし，その一部を とり還元糖を Somogyi 变法㫜で定量した。

2）粗濒粉一3)の $80 \%$ フルコールで抽出した残査 を全糖の場合と同様に加水分解を行ない糖を定量した。

3）還元糖一他の 1 組の試料を粉末とし， $80 \%$ 熱工 
タノールで 30 分間沸腾させ醳素反応を止め，抽出液を 除いてさらに新しい $80 \%$ エタノールを加えて加熱抽出 を 3 回絽返し，これらの抽出液をすべてあわせて減圧下 に浱樎, 酢酸鉛で除蛋白した後, 沪夜に莑酸カリウムを 加えて鉛を除去, 汇液の一定量をとり糖を定量, 一部は さらに減王濃縮しクロマトグラフィーで煻組成を検討 した。

4）可溶性糖一全糖から粗渐粉を減じたものを可溶性 糖とした。

3. ペーパークロマトグラフィー (PC)

東洋沪紙 No. 50 を用い, 展開郕はピリジン,ブタ, 一ル, 水 (6:4:3) で3 回多重展開を行なった。発色 片は酸性フタール酸アニリンとレゾルシンを使用した。

4. 薄層クロマトグラフィー（TLC）
クロマトプレートには Merck の Kieselgel Gを用 い, 展開剤は, ブタノール, インアミルアルコール, 水 $(10: 5: 4)$ で 3 回多重展開を行ない発色剤にはアニス アルデハイドを用いた。

\section{5. 遊離の糖の加水分解}

stachyose, raffinose, isomaltose 区分の加水分解は, $1 \mathrm{~N}$ 硫酸を 2〜4\%になるよ5に各抽出液に適量加え， $80 \sim 100^{\circ} \mathrm{C}$ で加水分解し, 岑酸 ハリウムで中和し沈知 を沪去した。isomaltose 区分の䣼素分解に用いた emul一 $\sin$ は市販 (東京化成) のものを用いた。

\section{実 験 結 果}

発芽に伴う蓄麦種子の糖含量の変化法 Fig. 1 に示さ れる。全糖, 粗澱粉共に発芽以後, 側根を生し肧軸の長

Fig. 1. Changes in Sugar Content during the Germination.

Values are expressed as $\mathrm{mg}$ per one individual

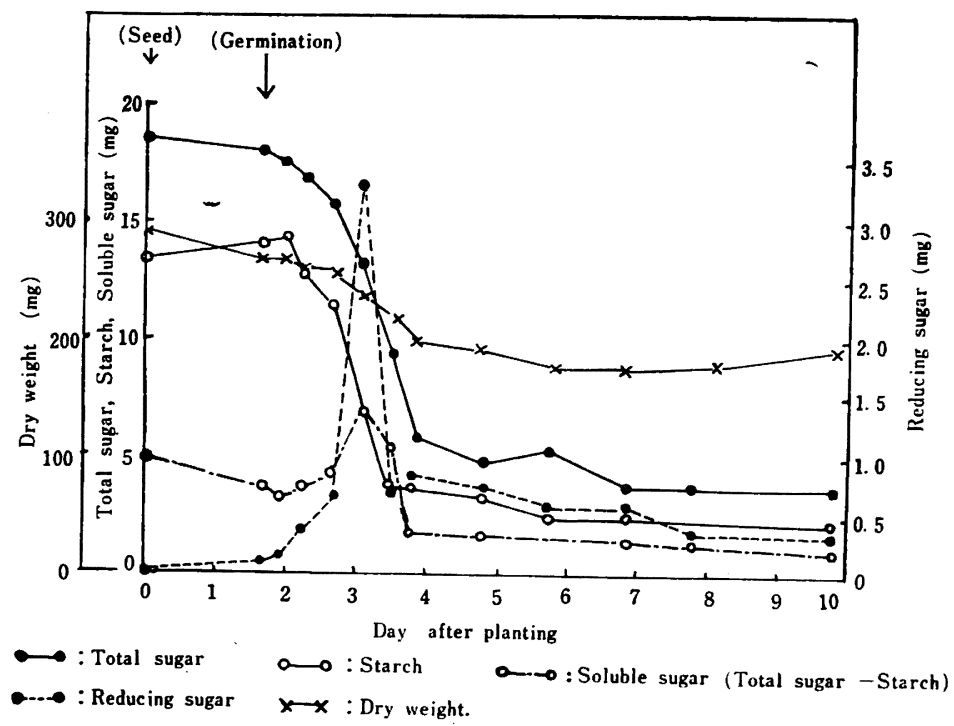

さ䄪 3 3 3.5 $5 \mathrm{~cm}$ まで（播種後約 4 日）急激な减少を示 し, 同時に可溶性糖, 還元糖が增加，4 日目以降はいず れすほほ平衡状態にあることがわかった。生体の乾燥重 量も全磄と同しょうな変化を示した。

各発育段階の遊離糖の組成を調べるために TLC と PC を行なった。その結果は Fig. 2, 3 に示される。TLC では glucose, fructose, sucrose, isomaltose, raffinoseの 位㯰とさらにその下に明らかなスポットを認め, 他にも 2,3のスポットが認められたがそれらは, はっきりとした 糖とは認め難かった。PC では, 上述の糖 6 個のスポット とisomaltotriose と考えられるスポットが認められ一番 下のスポットが stachyose に相当することがわかった。
またケトースに特有の発色剤であるレゾルシンによっ $\tau$, fructose, sucrose, raffinose, stachyose に相当す るスポットが明らかにケトース反応を呈した。さらに, raffinose, stachyose, isomaltose のスポットの部分を PC で分離, 切抜いて水で抽出を行ない加水分解したと ころ Fig. 4 に示すよ 5 に raffinose, stachyose 区分か らは, fructose, glucose, galactose を生じ, isomaltose 区分からは, glucose を生ずることを認めた。このこと より, raffinose, stachyose の存在することを確認した が, isomaltose は $\beta-1,6$ 結合をるつ gentiobiose と同 じ位圈を示すことが知られている ${ }^{11)}$ ので emulsin と酵 母の $\alpha$-glucosidase ${ }^{12)}$ を作用させたところ前者では全 
Fig. 2. Thin-layer Chromatography of Free Sugars from Buckwheat during the Germination

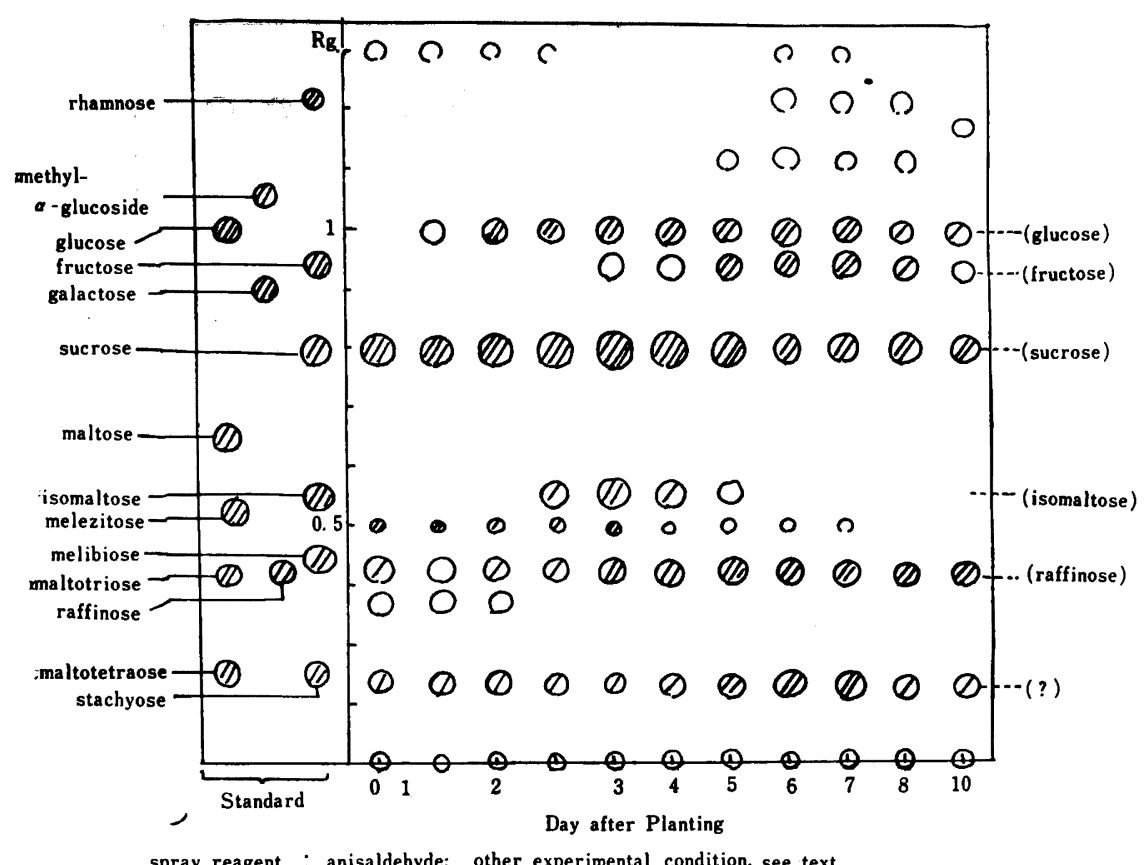

spray reagent : anisaldehyde; other experimental condition, see text.

Fig. 3. Paper Chromatography of Free Sugars from Buckwheat during the Germination

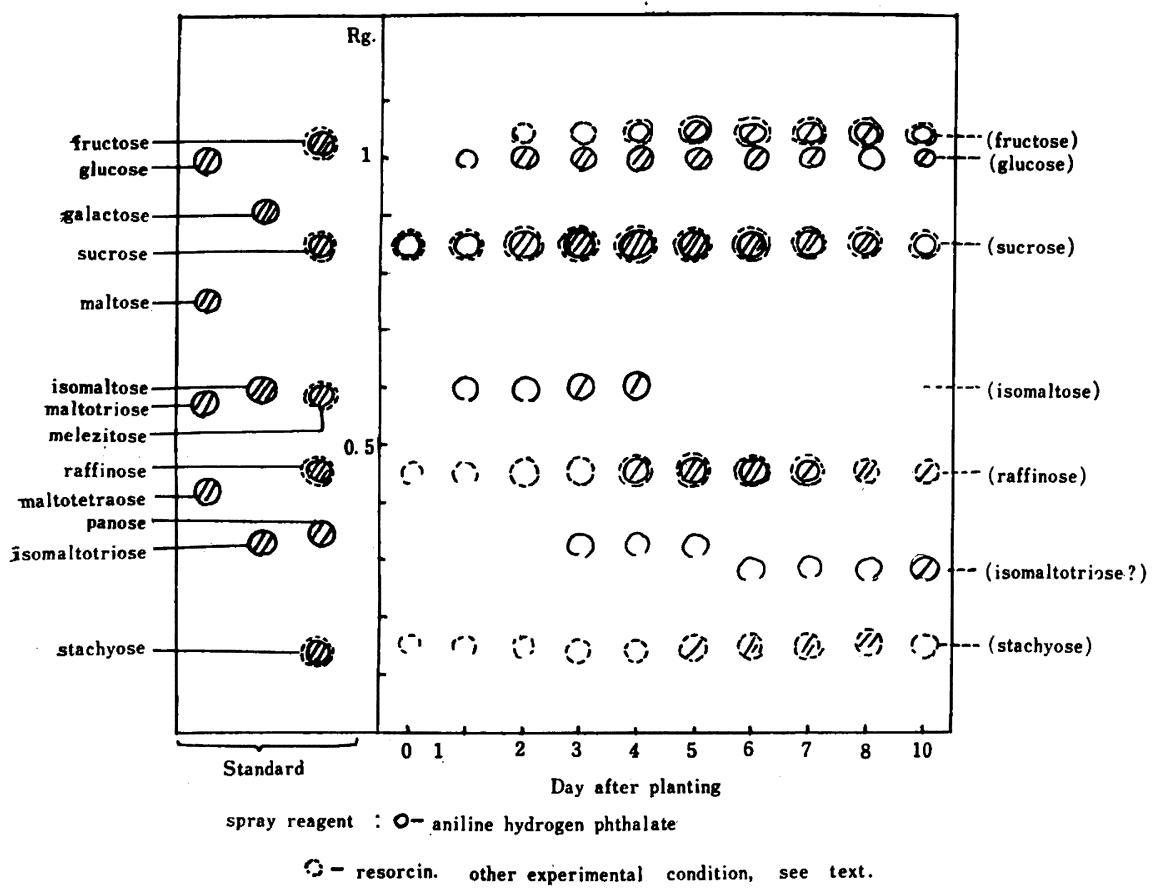


Fig. 4. Paper Chromatography of Hydrolysates of Raffinose, Stachyose and Isomaltose Fractions

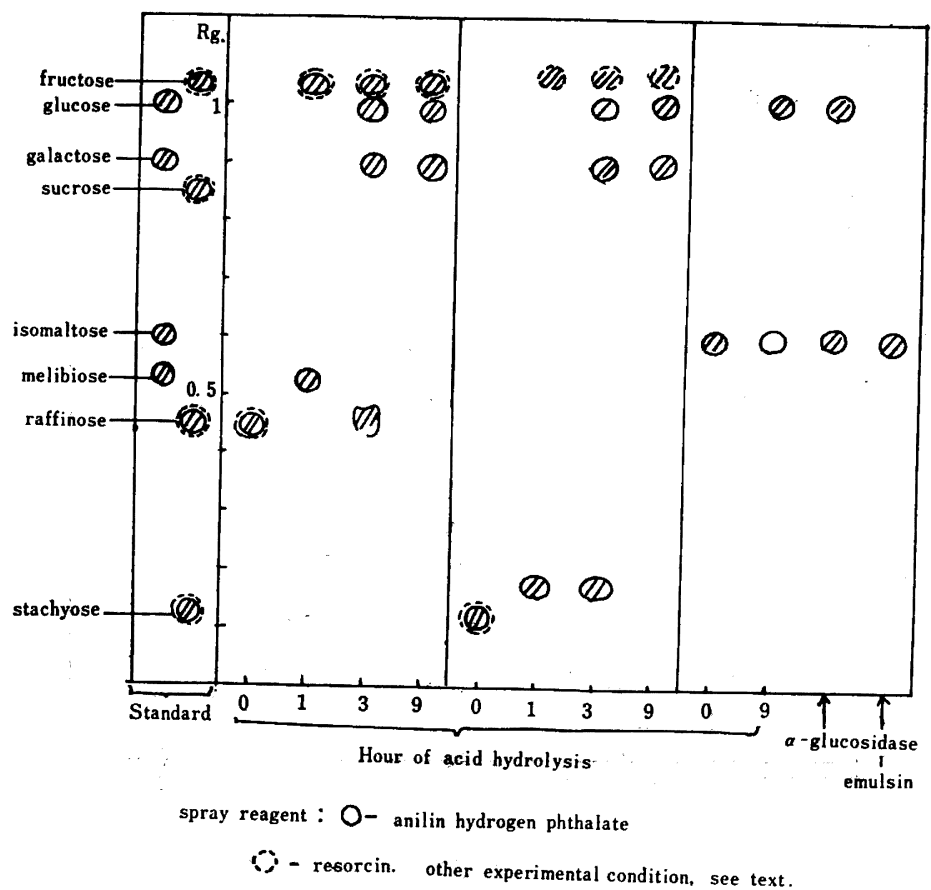

く分解されず，後者で分解されたこと（Fig. 4) より， isomaltose と確認した。（なお，Fig. 2,3,4 のスポッ トの濃淡は同一抽出液中の濃度差のみを示している。

以上の結果より, 未発芽種子には sucrose, raffincse, stachyose が存在し, 発芽後もこれら 3 種の糖は継続し て存在し, さらに glucose と fructose が生じ, 発芽中 期（播種後 2 5 日目）には isomaltose が，発芽後期 （播種後 3〜10 日目）には isomaltotriose と考えられ るスポットが認められることがわかった。 fructose は glucose 上り遅くに現われ，また同一抽出液中の raffinose, stachyose の割合は発芽後期に高くなっているこ とがわかった。

\section{要約}

帛麦種子について発芽に伴う糖含量と糖組成の变化を 検討した。

その結果, 発芽に伴って全糖, 粗濒粉か著しく減少, 同時に可溶性糖, 還元糖が增加, やがていずれ子平衡状 態になることがわかった。

糖組成をみると未発芽種子には sucrose, raffinose, stachyose が存在し, 発芽後もこれら 3 種の糖は継続し
て存在し,この他に glucose とやや遅れて fructose が 認められ，また発芽中期には isomaltose が, 後期には isomaltotriose (?) が認められた。発芽全期を通して sucrose 含量は常に一番高く, 発芽後期には raffinose, stachyose の割合が高まる傾向を示した。

$$
\text { 文献 }
$$

1) 福井俊郎, 二国二郎 : 農化, 33, 72 (1959)

2) 寺岡 宏: 北星女短大紀, 6, 62 (1960)

3）服部静夫, 代谷次夫 : Arch. Biochem., 34, 121 (1951)

4) H. Wanner: Ber. Schweiz. botan. Ges., 60, 426 (1950); 62, 205 (1952)

5) D. Koller, A. M. Mayer, A. Polijakoff-Mayber \& S. Klein: Ann. Rev. of Plant Physiol., 13, 451 (1962)

6) 中山 包: 発芽生理学, p. 97 (1960), 内田老鶴 围

7）松下アヤコ：農化，40，289 (1961)

8) B. Drews, H. Specht \& I. J. Pieper: Chem. Abstracts, 59, 13316 (1963)

9）小林達吉, 田淵武士：農化, 28, 171 (1954)

10) S. Chiba \& T. Shimomura: Agr. Biol. Chem., 26, 787 (1962)

11）山内文男, 松田和雄: 化学の 領 域, 18,689 (1964)

(北海道大学農学部農芸化学科) 